\title{
Acute radiation syndrome (ARS) - treatment of the reduced host defense
}

This article was published in the following Dove Press journal:

International Journal of General Medicine

27 January 2012

Number of times this article has been viewed

\section{Lars Heslet ${ }^{\prime}$}

Christiane Bay ${ }^{2}$

Steen Nepper-Christensen ${ }^{3}$

'Serendex ApS, Gentofte;

${ }^{2}$ University of Copenhagen,

Medical Faculty, Copenhagen;

${ }^{3}$ Department of Head and Neck

Surgery, Otorhinolaryngology,

Køge University Hospital, Køge,

Denmark
Correspondence: Steen Nepper-

Christensen

Department of Head and Neck Surgery, Otorhinolaryngology, Køge University Hospital

Lykkebækvej I, 4600 Køge, Denmark

Tel +4547313810

Email nepper@dadlnet.dk
Background: The current radiation threat from the Fukushima power plant accident has prompted rethinking of the contingency plan for prophylaxis and treatment of the acute radiation syndrome (ARS). The well-documented effect of the growth factors (granulocyte colony-stimulating factor [G-CSF] and granulocyte-macrophage colony-stimulating factor [GM-CSF]) in acute radiation injury has become standard treatment for ARS in the United States, based on the fact that growth factors increase number and functions of both macrophages and granulocytes.

Methods: Review of the current literature.

Results: The lungs have their own host defense system, based on alveolar macrophages. After radiation exposure to the lungs, resting macrophages can no longer be transformed, not even during systemic administration of growth factors because G-CSF/GM-CSF does not penetrate the alveoli. Under normal circumstances, locally-produced GM-CSF receptors transform resting macrophages into fully immunocompetent dendritic cells in the sealed-off pulmonary compartment. However, GM-CSF is not expressed in radiation injured tissue due to defervescence of the macrophages. In order to maintain the macrophage's important role in host defense after radiation exposure, it is hypothesized that it is necessary to administer the drug exogenously in order to uphold the barrier against exogenous and endogenous infections and possibly prevent the potentially lethal systemic infection, which is the main cause of death in ARS.

Recommendation: Preemptive treatment should be initiated after suspected exposure of a radiation dose of at least $\sim 2$ Gy by prompt dosing of $250-400 \mu \mathrm{g}$ GM-CSF $/ \mathrm{m}^{2}$ or $5 \mu \mathrm{g} / \mathrm{kg}$ G-CSF administered systemically and concomitant inhalation of GM-CSF $~ 300$ mcg per day for at least 14-21 days.

Conclusion: The present United States standard for prevention and treatment of ARS standard intervention should consequently be modified into the combined systemic administration of growth factors and inhaled GM-CSF to ensure the sustained systemic and pulmonary host defense and thus prevent pulmonary dysfunction.

Keywords: inhaled and systemically administered GM-CSF, ARS, host defense, orchestration of pulmonary host response

\section{Introduction}

The present review is based on reported experiences from inadvertent radiation exposure during acute radiation accidents and on a literature search taking into account the newest documentation about the benefit of administering growth factors (granulocyte colony-stimulating factor [G-CSF]/granulocyte-macrophage colony-stimulating factor [GM-CSF]). Exposure with a high dose radiation induces the so-called acute radiation syndrome (ARS) followed by severe injury to stem cells, organs, and tissues. ${ }^{1}$ The seriously-affected patient with bone marrow aplasia will experience reduced defense 
against exogenous and endogenous factors, such as infection and inflammation, and consequently suffer from invasive infection and organ dysfunction, which may be relieved by allogenous hematopoietic stem cell transplantation (HSCT), ${ }^{2-4}$ although treatment results are not encouraging. In extreme cases, the radiation injury may be fatal for the exposed person..$^{4-7}$ All organs may be affected and damaged. However, airways are potentially exposed to a "double hit injury" in that the lungs receive exposure to gamma irradiation along with the rest of the body as well as potential radiation from inhaled radioactive dust particles.

\section{ARS}

ARS is a combination of acute injury manifestations that occur after a sufficiently large portion of the body is exposed to a high dose of ionizing radiation. ARS is defined as the signs and symptoms that occur after a whole-body or significant partial-body (60\%) exposure of $>1$ Gy total dose, delivered acutely at a relatively high-dose rate. Such irradiation injury initially affects all organs to some extent, but the timing and extent of the injury manifestations depend upon the type, rate, and dose of radiation received. ${ }^{4}$ The percentage of the body that is injured, the dose homogeneity, and the intrinsic radiosensitivity of the exposed individual also influence manifestations. Different ranges of whole-body doses produce different manifestations of injury. The three main ranges that produce the most characteristic manifestations are referred to as the hematological, gastrointestinal, and neurovascular syndromes. These syndromes are, as a rule, produced only with whole-body or near whole-body irradiation by photon or mixed photon/neutron radiation. High-dose injuries to smaller percentages of the body produce local injury effects, but may not cause ARS. ${ }^{4,5}$

Radiation damage primarily affects proliferating cells because they are the most sensitive to acute effects. ${ }^{2}$ The tissues therefore have different sensitivity thresholds for the release of clinical symptoms after radiation. Bone marrow and the intestines have a low threshold caused by fast cellular turnover, whereas muscles and brain cells multiply slowly and are more resistant to radiation. The clinical components of ARS include several subsyndromes, each with a specific trigger sensitivity threshold for the release of clinical symptoms like the hematologic, gastrointestinal, cerebrovascular, and multiorgan/pulmonary dysfunction syndromes (Table 1).

Each syndrome can be divided into four phases: prodromal, latent, manifest illness, and recovery or death. ${ }^{2-4,8-10}$ The time course and severity of clinical signs and symptoms
Table I Overview of acute radiation syndrome (ARS) following exposure to radiation ${ }^{2}$

Dose response in respect to radiation injury

- ARS is the host response against exogenous radiation injury, which may be fatal for the exposed person

Organ dysfunction in ARS

- Even at low irradiation doses bone marrow stem cells will be affected, and thus neutrophils, monocytes, and erythrocytes

- The function of organ fixed macrophages will also be harmed, which in turn will reduce outermost host defense barrier

Prophylactic treatment of ARS

- Conventional treatment and supportive care in ARS have limited effect on recovery from elevated levels of radiation exposure

- The only effective intervention to date in reducing the mortality in ARS is treatment with growth factors: granulocyte colony-stimulating factor and granulocyte-macrophage colony-stimulating factor, which have a documented positive effect on recovery from ARS $S^{8,9}$

for ARS subsyndromes at different dose ranges are reviewed in Table 2.

The most sensitive cells to acute radiation effect are in bone marrow. However, an overlooked fact is that there are other important replicative cells, namely the fixed tissue macrophages in tissue and vital organs. Depending on the absorbed radioactive dose, symptoms appear within hours to weeks, following a predictable clinical course. The prodromal phase of ARS usually occurs in the first 48 hours, but may develop up to 6 days after exposure. ${ }^{2}$ The latent phase is a short period characterized by improvement of symptoms as the person appears to have recovered. Unfortunately, this effect is transient, lasting for several days to a month.

Symptoms of manifest illness then appear and may last for weeks. This stage is characterized by intense immunosuppression and is the most difficult to manage. If a person survives this stage, recovery is likely. Individuals exposed to a supralethal dose of radiation deteriorate over a period of hours, resulting in early death. ${ }^{4,5}$

Symptoms of acute, high-dose radiation are dependent on the absorbed dose. They may appear within hours to days and follow a somewhat predictable course. ${ }^{12}$ Early symptoms resulting from an acute whole-body exposure constitute the prodromal radiation syndrome. Virtually all individuals receiving a dose of 10-20 Gy develop prodromal signs and symptoms within 1-72 hours after exposure. ${ }^{2,4,5}$ The initial clinical picture is most often dominated by gastrointestinal signs and symptoms (Table 2) primarily resulting from central nervous system manifestations due to the location of the control center of anorexia, nausea, and vomiting in the brain. Central nervous system dysfunction may be evident early on by changes in the electroencephalography, even at much lower doses. In later phases, the symptoms gradually 


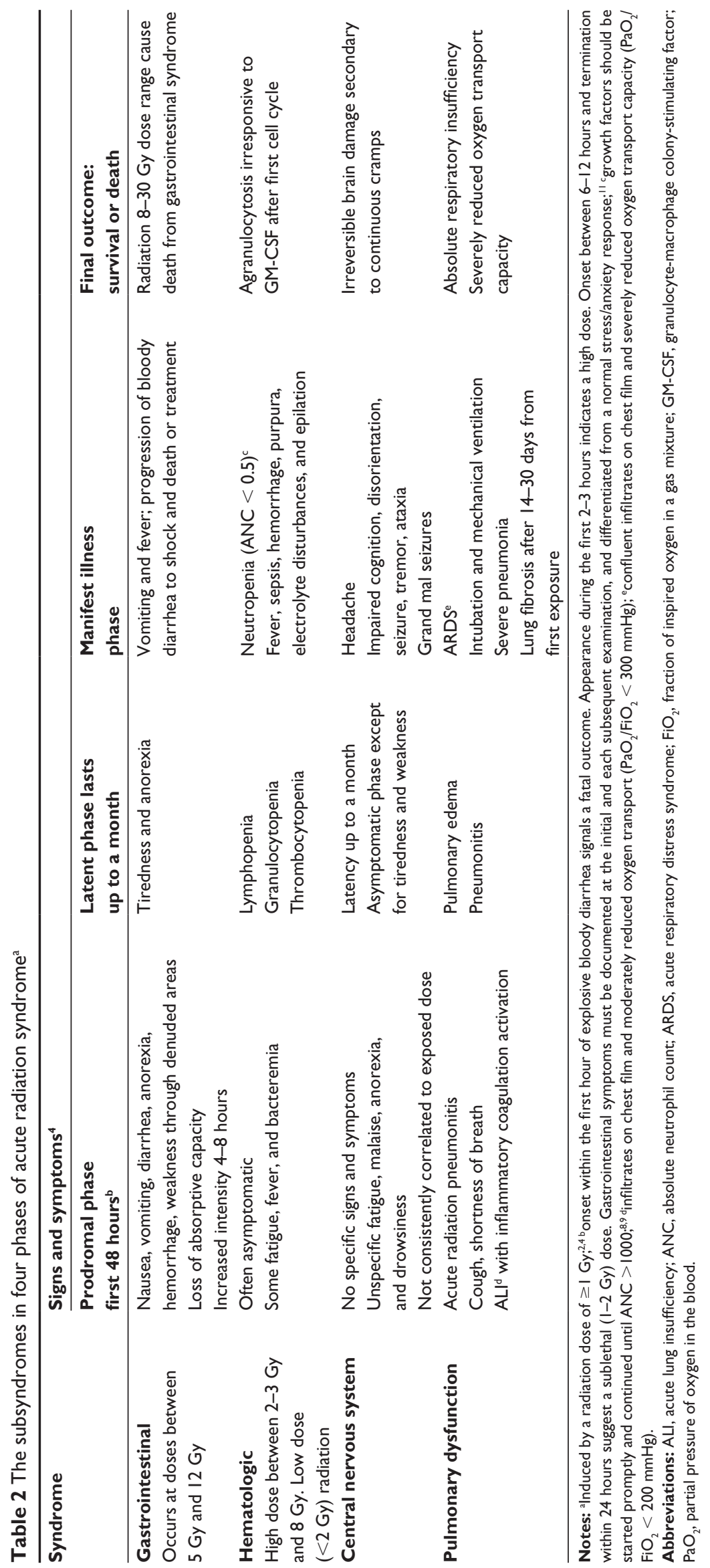


merge into loss of consciousness, hypotension, and death (components of the cerebrovascular syndrome that is characterized by neurologic failure and cardiovascular collapse) before toxicity to other organ systems (such as the gastrointestinal and hematologic systems) can develop.

Death occurs within a few days after exposure to 10-20 Gy, in absence of treatment. ${ }^{4,5}$ A rapid, severe prodromal response is the harbinger of a poor clinical outcome that is complicated by severe leukoneutropenia, thrombocytopenia, and anemia with reticulocytopenia, accompanied by hemorrhage, infection, and death. At lower doses (2-10 Gy), it is difficult to establish a prognosis based on the prodromal phase. The prodromal phase is followed by a phase of manifest illness where syndromes specific to various organ systems emerge. Four major organ subsystems are known to be of critical significance in the development of ARS: the gastrointestinal system, neurovascular system, hematologic system, and pulmonary system. Evaluation of system-specific signs and symptoms is required for triage of victims, selection of therapy, and determination of prognosis. ${ }^{13}$

\section{The hematologic syndrome}

The present paper emphasizes the hematologic subsyndrome based on the fact that growth factors have an important prophylactic effect on survival, provided that treatment is administered promptly. ${ }^{14-17}$ The earliest presentation of ARS is the hematologic syndrome. ARS may be observed in patients who receive whole-body doses $\sim 1 \mathrm{~Gy}$, but generally it is not clinically significant at doses $\sim 2$ Gy unless other combined injuries are present. ${ }^{9}$ The overlap of other organ damage with hematologic syndrome would be observed if patients survived long enough to manifest aplasia. ${ }^{5}$

Dose-dependent myelosuppression develops over 1 week..$^{2,3}$ Dose-dependent extramedullary toxicity also complicates management and increases mortality. Patients with radiation injury and burns or significant trauma have combined injury syndrome which is associated with a high mortality rate, even at lower radiation doses and with lesser bone marrow injury. ${ }^{3,4}$ In a mass casualty scenario, priority of treatment is based on the severity of patients' condition, ie, the triage process, which sees radiation victims offered comfort care only. ${ }^{9,13}$ Granulocytes may transiently increase in patients with exposure of 5 Gy. This transient "abortive rise" before neutropenia may suggest a better prognosis. ${ }^{18}$

The nadir of neutrocytes can take 1-4 weeks to occur, with a longer time to nadir at lower doses (Table 3)., ${ }^{2,418-20}$ These patients are still exposed to high risk as the duration of neutropenia may be prolonged, requiring extended support
Table 3 Acute radiation syndrome imposes a critical hematopoietic response ${ }^{19,20}$

\begin{tabular}{|c|c|}
\hline $\begin{array}{l}\text { Hematopoietic } \\
\text { outcome }\end{array}$ & Predictors \\
\hline Reversibility & $\begin{array}{l}\text { Granulocytes: moderate granulocytosis, initial } \\
\text { increase with a nadir between } 4-10 \text { days. Secondary } \\
\text { increase day } 20-30 \\
\text { Lymphocytes: decline to nadir levels within } 2 \text { days, } \\
\text { thereafter slow recovery } \\
\text { Platelets: initial I0-day shoulder followed by decline } \\
\text { toward day } 20 \text {, nadir: days } 20-30\end{array}$ \\
\hline Irreversibility & $\begin{array}{l}\text { Granulocytes: initial granulocytosis and progressive } \\
\text { decline of cell counts between day } 4 \text { and day } 6 \\
\text { Lymphocytes: progressive decline within } 24 \text { hours } \\
\text { Platelets: progressive decline within the first } 10 \text { days }\end{array}$ \\
\hline
\end{tabular}

with hematopoietic growth factors, blood products, and antimicrobials. Patients with concomitant burns or traumatic injuries often show poor wound healing and bleeding, and without aggressive medical support, the mean lethal dose of radiation leads to $50 \%$ mortality at 60 days in a whole-body radiation dose of $\sim 3.5 \mathrm{~Gy}^{3}{ }^{3}$ This radiation dose increases to 6-7 Gy with optimal supportive care, antimicrobials, and transfusion support. ${ }^{8,9,13,21}$

\section{Survival requires hematologic recovery}

Management of patients with ARS includes early use of hematopoietic cytokines, antimicrobials, and transfusion support. Recommendations based on radiation dose and physiologic response is made for treatment of the hematologic syndrome, and therapy includes treatment with hematopoietic cytokines, blood transfusion, and, in selected cases, HCST. ${ }^{8,9,13}$

Additional medical management based on the evolution of clinical signs and symptoms includes the use of antimicrobial agents (quinolones, antiviral therapy, and antifungal agents), antiemetic agents, and analgesic agents. Because of the strong psychological impact of possible radiation exposure, psychosocial support is required for those exposed, regardless of the dose.

The prevention and management of infection is the mainstay of therapy. There is a quantitative relationship between the degree of neutropenia and the increased risk of infectious complications. ${ }^{89}$ Antibiotic prophylaxis should only be considered in afebrile patients at the highest risk for infection. These patients have profound duration of more than 7 days neutropenia (eg, measured in whole blood as absolute neutrophil count $<500 / \mathrm{mL}$ ). Although the degree of neutropenia is the greatest risk factor for developing infection, 
other factors influence treatment choice and outcome. Such factors include duration of neutropenia, bactericidal functionality of surviving neutrophils, alteration of physical defense barriers, the patient's endogenous microflora, and organisms endemic to the hospital and community. ${ }^{19}$ As the duration of neutropenia increases, the risk of secondary infections such as invasive mycoses also increases. ${ }^{19}$

It is for these reasons that adjuvant therapy such as the cytokines sargramostim (GM-CSF [Leukine ${ }^{\circledR}$; Immunex, Seattle, WA] ) and filgrastim (G-CSF [Neupogen ${ }^{\circledR}$; Amgen, Inc, Thousand Oaks, CA]) will prove invaluable in the treatment of the severely irradiated person, although only sparse data is available..$^{8,9}$ The treatment recommendations on irradiation-associated aplasia are based on the known effect of CSF's beneficial effect on recovery of neutrophils in oncology and hematology patients ${ }^{22-27}$ and in recipients of bone marrow transplantation, ${ }^{28-32}$ on their seemingly positive role on hematological recovery in a small number of radiation accident victims, ${ }^{7,14-17}$ and, most importantly, on the improved survival and positive effects on neutrophils in a number of well-conducted studies of animals exposed to radiation. ${ }^{33-42}$

\section{Treatment with growth factors}

Cytokines include GM-CSF, macrophage CSF, G-CSF, stem cell factor, and interleukin series (interleukin-1 to interleukin-16). GM-CSF and G-CSF have been available since 1997 for the treatment of radiation myelosuppression. G-CSF, also known as filgrastim, is administered in a dose of 100-200 $\mathrm{mcg} / \mathrm{m}^{2} /$ day and GM-CSF, also known as sargramostim, is administered in a dose of $200-400 \mathrm{mcg} / \mathrm{m}^{2} /$ day. Both are given intravenously or subcutaneously. Both drugs should be initiated promptly upon diagnosis of significant bone marrow damage and continued until recovery of neutrophil counts is sustained above $800 / \mathrm{mm}^{3} .{ }^{9}$

G-CSF and GM-CSF are currently in widespread clinical use for the treatment of acute neutropenic conditions, and in turn are used in the management of infections following radiochemotherapy of cancer patients. Both of these agents are potent but selective stimulators of granulopoietic arm of the hematologic system, and serve not only to increase blood neutrophil counts but also to enhance the maturation and function of these vital cells (Figure 1). Both agents have high therapeutic ratios, minimal nonperformance side adverse effects, can be administered and monitored with relative ease, and can effectively serve to minimize the risk of infection resulting from a radiation-compromised lymphohematopoietic system.
G-CSF and GM-CSF are potent stimulators of hematopoiesis and effective in reducing duration and degree of neutropenia. An additional benefit of CSFs is their ability to increase functional capacity of neutrophil and thereby contribute to the prevention of infection in an active role as cellular host. They constitute a remarkable advance in the treatment of neutropenia and are, thus, powerful tools for oncologists in the clinical management of cancer patients. The drugs act upon uncommitted stem cell populations within bone marrow to increase mitotic rate, accelerate repopulation, differentiate daughter cells to become committed stem cells, speed the maturation process, and improve the function of existing granulocytes (Figure 1). In this way, they improve the immune function of existing cells while speeding the recovery of stem cell populations, thus reducing the extent and duration of the white cell nadir and total compromise of the immune system.

Studies of cancer patients suffering from neutropenia consistently show that use of these cytokines reduces infection rates, admissions, and days hospitalized. ${ }^{23,25,27-29}$ GM-CSF and G-CSF have both been used for treatment of ARS because their effect on granulocytes and myeloid stem cell lines do not come at the expense of other marrow cell lines. In order to achieve maximum clinical response, G-CSF or GM-CSF should be started as soon as possible after exposure..$^{5-9,14}$ This provides the opportunity for maximum recovery. Cytokine administration should continue, with daily consecutive injections, to reach the desired effect of an absolute neutrophil count of $1000 / \mu \mathrm{L}$ after the absolute neutrophil count nadir (Table 4).

\section{Biodosimetry}

Individual biodosimetry is from a theoretical viewpoint essential for predicting subsequent clinical severity, morbidity, and mortality. A range of clinical "dosimetric" utility has been developed for bedside use, such as several biological indicators recently described. ${ }^{43-45}$ The method with the highest accuracy and considered the "gold standard"13 is the chromosomal aberration method, but the test usually takes 3-5 days to develop (Table 5). ${ }^{46,47}$

\section{Prompt treatment with growth factors in ARS Prophylactic intervention}

A number of papers document that a prompt initiation of treatment with growth factors implies an optimal outcome after radiation exposure, ${ }^{8,9}$ as the tissue macrophages will be transformed into fully matured immunocompetent dendritic 


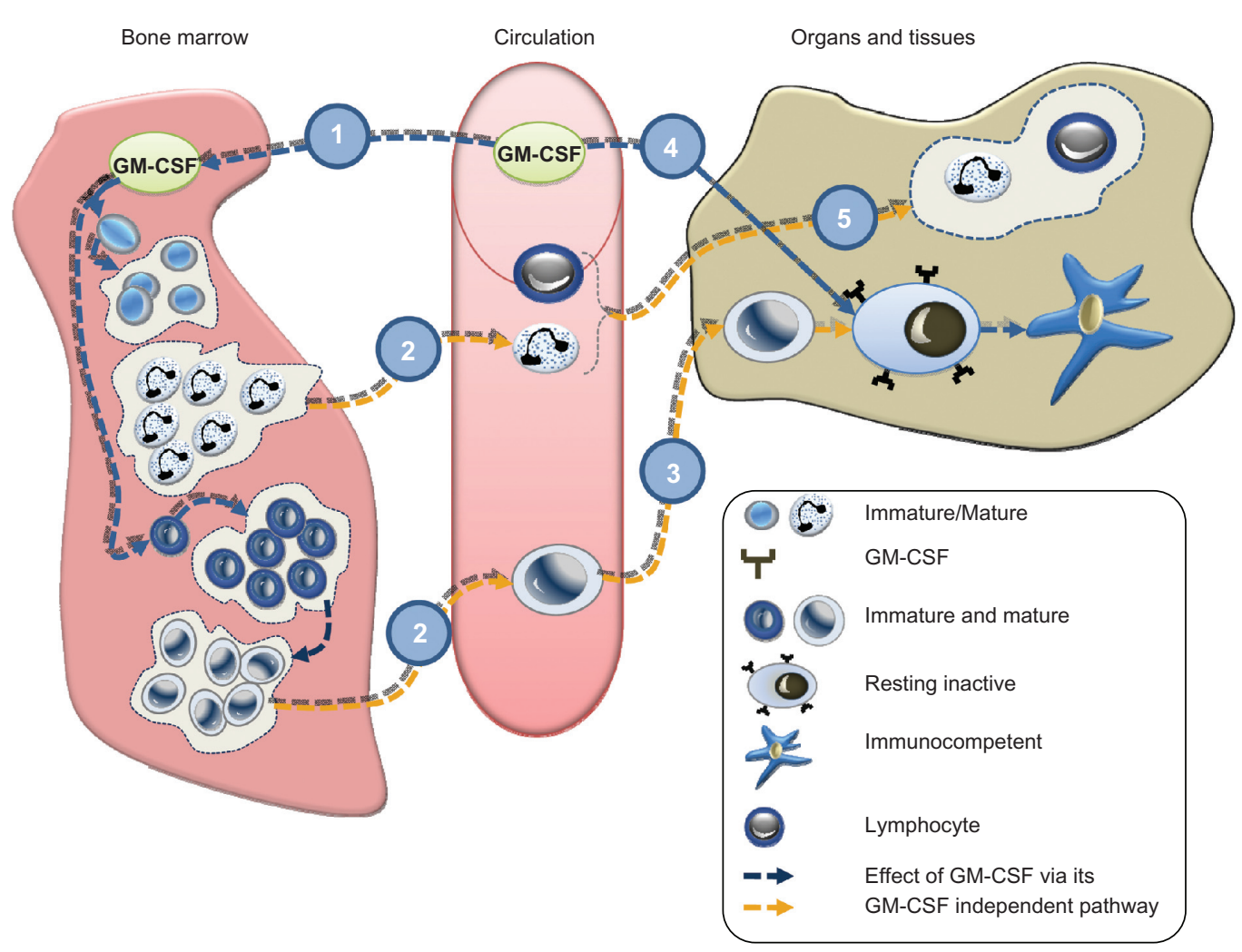

Figure I Systemic administration either by infusion or subcutaneous dosing of granulocyte-macrophage colony-stimulating factor (GM-CSF) activates the stem cells of neutrocytes and macrophages/monocytes. Consequently these cell lines maturate and proliferate (I). The circulating monocytes (2) become tissue macrophages, which are present in both bone marrow and peripheral organs including the lungs. The monocytes transform into tissue macrophages in tissue (3). After stimulation, GM-CSF receptors transform resting alveolar macrophages into immunocompetent dendritic cells corresponding to the autocrinic GM-CSF response locally (4), during which process both T-lymphocytes and granulocytes are being recruited from circulation (5). In acute radiation syndrome, cells in bone marrow and tissue macrophages stop participating in the host because the local GM-CSF is no longer expressed. As a consequence, host defense is reduced with a fatal lack of barriers against endogenous and exogenous microbiological agents, but the administration of GM-CSF via the subcutaneous/infusion route will normalize the host. However, macrophages in the lungs can only be reached by inhalation, the only way to upregulate and to protect the lung host.

cells in 7-10 days. This implies that preemptive intervention, or intervention initiated as early as possible after the radiation exposure, is the preferred intervention after an exposure of a high radiation dose, eg, whole-body exposure to a radiation dose of 2-3 Gy, at which time the number and function of the peripheral monocytes and neutrocytes are not yet affected. Treatment of ARS with GM-CSF ensures both quantitative and qualitative effect on all effector cells, ie, monocytes, tissue-bound macrophages, and neutrocytes (Figure 1), as G-CSF does not stimulate local maturation of

Table 4 Comparison of granulocyte-macrophage colony-stimulating factor (GM-CSF) and granulocyte colony-stimulating factor $(\mathrm{G}-\mathrm{CSF})^{14,22,23,37-39,41}$

\begin{tabular}{|c|c|c|}
\hline & GM-CSF & G-CSF \\
\hline Upregulating $^{\mathrm{a}}$ & Effect on monocytes, tissue macrophages, and granulocytes & Only effect on granulocytes \\
\hline Adverse effects & Fever, nausea, fatigue, headache, bone pain, myalgia & $\begin{array}{l}\text { Medullary bone pain observed shortly after } \\
\text { initiation of G-CSF treatment }\end{array}$ \\
\hline Dosing & $200-400 \mathrm{mg} / \mathrm{m}^{2} / \mathrm{day}$ & $5 \mu g / \mathrm{kg}$ body weight \\
\hline Initiation & $\begin{array}{l}\text { Promptly when significant } \\
\text { radiation dose is suspected }\end{array}$ & $\begin{array}{l}\text { Either promptly when significant radiation } \\
\text { dose is suspected or when } \\
\text { neutrocytes }<0.5 \times 10^{9}\end{array}$ \\
\hline Stopping criteria & Neutrocytes increasing, eg, $>1.0 \times 10^{9} \mathrm{ANC}^{b}$ & Neutrocytes increasing, eg, $>1.0 \times 10^{9} \mathrm{ANC}$ \\
\hline Route of administration & Subcutaneous/Infusion/Inhalation & Subcutaneous/Infusion \\
\hline
\end{tabular}

Notes: ancludes both quantitative (increased number) and qualitative (improved maturation and function) related variables effects; ${ }^{\mathrm{b}}$ stopping criteria should be based on the response of macrophage activation, however, this variable cannot be measured, therefore the stopping criteria of G-CSF is applied.

Abbreviation: ANC, absolute neutrophil count. 
Table 5 Comparison of dosimetric methods and their utility ${ }^{18,46,47}$

\begin{tabular}{lll}
\hline Dosimetry & Methods & Utility \\
\hline Biological & Whole-body counting & $\begin{array}{l}\text { Not practical, generally } \\
\text { not available }\end{array}$ \\
& $\begin{array}{l}\text { Chromosomal aberrations } \\
\text { (dicentrics and ring forms) }\end{array}$ & $\begin{array}{l}\text { The "gold standard," } \\
\text { however it takes 4-5 days } \\
\text { processing time } \\
\text { In spite of high }\end{array}$ \\
& & practicability, clinical \\
Clinical & Signs and symptoms & dosimetry has low \\
& & sensitivity particularly \\
& & at low doses \\
\hline
\end{tabular}

resting and immunoincompetent macrophages. In organs and tissues, these cells will mediate their front defense bastion in relation to the immune defense. The activated macrophages orchestrate the overall actions and recruitment of systemic host cells like the lymphocytic cells and neutrophils, ensuring and maintaining a normal host barrier function in respect to endogenous and external biological agents in the hypoplastic or aplastic ARS patient. Macrophages are found in all human tissues, not only in bones, skin, and mucosa (eg, of the gut, eye, peritoneum, and meninges), but also in all organs including lungs, kidneys, heart, central nervous system, pericardium, pleura, and liver. Only GM-CSF, and not C-CSF, activates macrophages by production from location-specific tissue cells. Therefore, in the sealed-off compartment of the lungs, activation of the macrophages can only be achieved by stimulation of GM-CSF, either by local production or by inhalation (Figure 2).

\section{Local pulmonary host defense and ARS}

There has recently been a discussion whether recombinant proteins should be inhaled or administered systemically in order to achieve a pulmonary effect by reaching the alveolar receptors ${ }^{48}$ The question is then, which is the preferred route when intervening with GM-CSF?

In bone marrow, stem cells, and all organs, macrophage activity is enhanced by the systemic administration of GM-CSF dosing. In a radiation disaster, the lungs receive a comparable dose of radiation as the rest of the body, but as the lungs depend solely on local endogenous GM-CSF expression by alveolar macrophages, the endogenous GMCSF produced from systemic tissues does not penetrate across the alveolar capillary barrier.

It has been documented that inhaled GM-CSF increases the number and function of phagocytic cells from bronchoalveolar lavage, but only a sparse and transient increase in the number of myeloid cells in circulation. ${ }^{34}$ When administered intravenously, however, there is only a limited response in alveolar cellularity. It follows that pulmonary innate host defense is separated from the systemic defense system in respect to
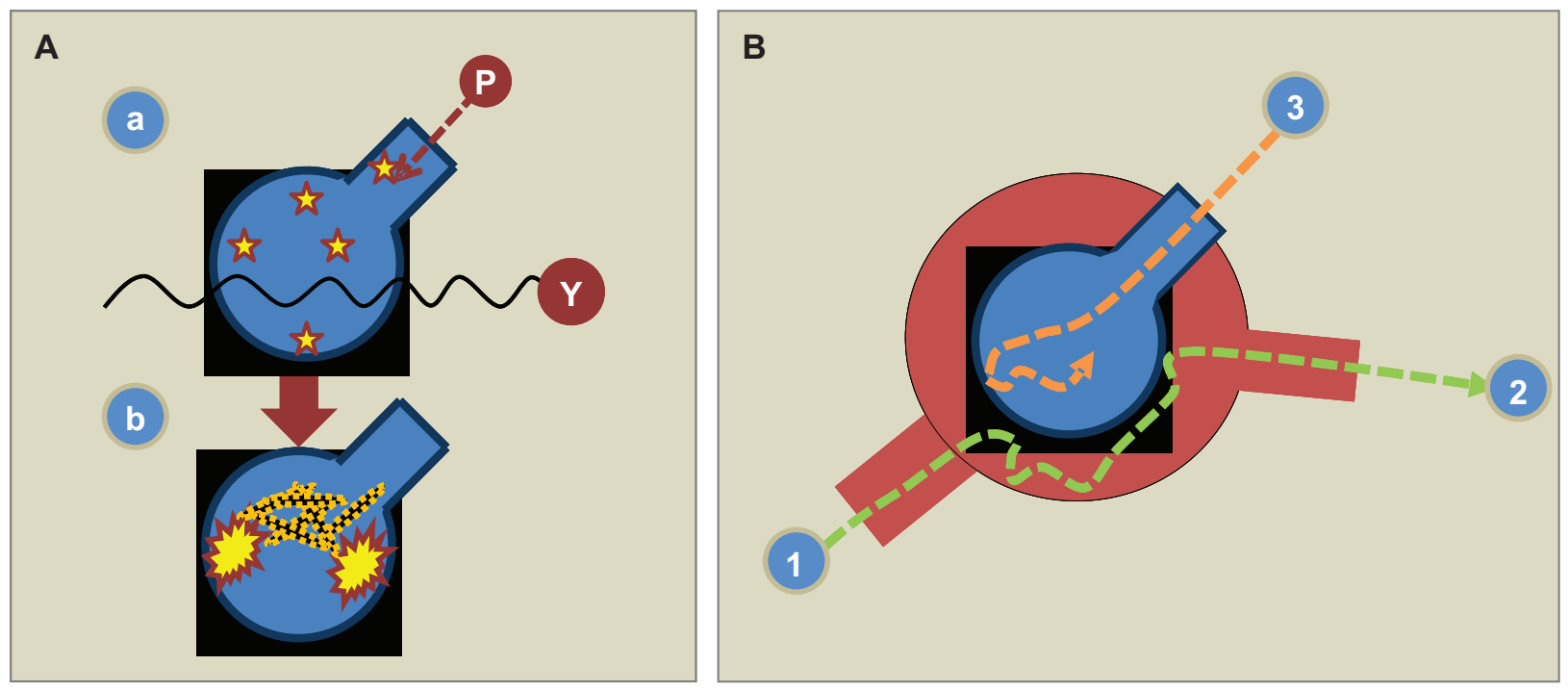

Figure 2 (A) The lung is the most vulnerable vital organ when exposed to acute irradiation because of the "double hit" radiation exposure, ie, a combined exposure of inhaled particles (P) and from gamma radiation $(\gamma)$ similar to the rest of the body (a). The lung host is dependent on its local granulocyte-macrophage colony-stimulating factor (GM-CSF) being expressed by alveolar cells. Intravenous or subcutaneous administration of GM-CSF does not reach its target in the alveolar space as it is "sealed off" from the airspace due to its water solubility and molecular size. ${ }^{34}$ In order to upregulate the pulmonary host by activating the resting alveolar macrophages (Figure I), GM-CSF has to be inhaled. Due to radiation injury, the lung is accordingly exposed to severe dysfunction. GM-CSF does not penetrate the alveolocapillary membrane from "the blood side" to "the air side" or vice versa. (B) When GM-CSF is administered systemically (I), it "bypasses the alveolocapillary membrane" and via pulmonary circulation reaches the remaining tissues and organs (2). The only way to upregulate the pulmonary host is to inhale GM-CSF (3). 
Table 6 Candidates for bone marrow transplantation ${ }^{8,9}$

\section{First step}

Prompt growth factor intervention

Second step

Final evaluation for candidates for HSCT
In the case of aplasia in relation to acute radiation syndrome, emergency HSCT is not necessary G-CSF/GM-CSF promotes hematological reconstruction and should be evaluated after prompt administration and after 14 days of high dose GM-CSF administration

HSCT should only be implemented after residual hematopoiesis and only considered if severe aplasia persists after long G-CSF/GM-CSF high-dose treatment

Abbreviations: G-CSF, granulocyte colony-stimulating factor; GM-CSF, granulocyte-macrophage colony-stimulating factor; HSCT, hematopoietic stem cell transplantation.

GM-CSF, and that biologics ${ }^{\mathrm{a}}$ does not penetrate from systemic circulation to the alveolar space. ${ }^{34}$ It has been documented that when administered intravenously, only $2 \%$ of smaller molecules such as recombinant antitrypsin reach the alveolar space. ${ }^{49}$ In larger molecules, such as recombinant activated protein $\mathrm{C}$, there is no effect when administered intravenously, ${ }^{50}$ however when inhaled, activated protein $\mathrm{C}$ achieves the expected effect in the alveolus with no adverse effects. ${ }^{51,52}$

An important point is whether the inhaled drug reaches the GM-CSF receptors of alveolar macrophages in the peripheral airways. By using a micropump nebulizer, sufficiently small respirable aerosol particles with a size of $\sim 2.5 \mu \mathrm{m}$ are produced which means that a high degree of peripheral lung deposition is obtained. . $^{53,54}$

It has been thoroughly documented that there are no known adverse effects in relation to administering inhaled GM-CSF, even when administered in very high doses. ${ }^{23,24,55-57}$

\section{Inhaled GM-CSF in antiradiation intervention in ARS}

Inhaled GM-CSF in antiradiation intervention maintains lung host defense and prevents severe pneumonia with endogenous microbiological agents such as viruses, bacteria, and fungi. Inhaled GM-CSF should be administered promptly and concomitantly with systemic intervention in the antiradiation therapy regime. The initial dose should be $\sim 300 \mu \mathrm{g} /$ day up to $300 \mu \mathrm{g} / \mathrm{m}^{2}$ daily depending on the response. ${ }^{9}$ The inhaled drug is effective and has no adverse effect even in the very high dose range, making it highly recommendable in ARS. ${ }^{7,9,14}$

\section{Overall plan for care of irradiation victims}

Management of the hematologic syndrome, as a component of acute radiation sickness, requires understanding of its manifestations and implementation of clinical biodosimetry

${ }^{a} \mathrm{~A}$ medicinal product, such as recombinant therapeutic proteins like GM-CSF, that is produced by biologic processes. to provide appropriate therapeutic support. Hematopoietic growth factors may be of value if administered early as a component of supportive care. Planning for urgent HSCT for those with intermediate- to high-dose radiation (4-10 Gy) may be required (Table 6), ${ }^{4,5,8,9,14,58}$ although the use of HSCT is controversial as outcomes after radiation accidents have been poor. ${ }^{59,60}$ Establishing contingency plans for triage, assessment, supportive care, and treatment with defined eligibilities, treatment plans, and incorporated data collection to assess results and plan further improvements in care is imperative for the effective management of large scale radiation accidents. ${ }^{13}$ The hematology/oncology community is most suited to participate in such contingency planning. ${ }^{21}$

\section{Timing of treatment with growth factors}

In the case of a nuclear event, it is likely that it would take many hours, if not days, to estimate the radiation exposure for each patient; thus, in any adult with an expected exposure greater than 2 Gy, treatment with growth factors should be initiated as soon as biodosimetry results suggest that such an exposure has occurred or when clinical signs and symptoms indicate a serious level of hematotoxicity, while there may be initial granulocytosis followed by significant neutropenia. ${ }^{8,9}$ Growth factor treatment should be continued throughout this entire period in order to not overlook reversible aplasia, and as discussed in detail in this review,

Table 7 Treatment of acute radiation syndrome with growth factors, a proposed new preemptive treatment regime

\begin{tabular}{ll}
\hline $\begin{array}{l}\text { Growth factor } \\
\text { Systemic therapy }\end{array}$ & GM-CSF: s.c. or infusion $400 \mu \mathrm{g} / \mathrm{m}^{2 a}$ \\
& GM-CSF: s.c. or infusion $5 \mu \mathrm{g} / \mathrm{kg}$ \\
Local pulmonary & GM-CSF: inhalation $400 \mu \mathrm{g}$ per day \\
\hline
\end{tabular}

Notes: Growth factors should be administered promptly after radiation exposure by sufficient dosing to promote early hematological recovery. aSquare meter body surface; 'breferably use micropump nebulizer, eg, Aeroneb ${ }^{\circledR}$ nebulizer system (Aerogen Ltd, Galway, Ireland), as this type of nebulizer does not interfere with the active sites of the molecule.

Abbreviations: G-CSF, granulocyte colony-stimulating factor; GM-CSF, granulocyte-macrophage colony-stimulating factor; s.c., subcutaneously. 
recommendations should include both a systemicallyadministered dose of growth factor G-CSF/GM-CSF and an inhaled dose of GM-CSF to ensure maximal response and protection from infection (Table 7).

\section{Conclusion}

Medical management of victims exposed to intentional or accidental radiation is complex and demands many resources. The primary responsibility for optimizing outcome resides with hospital staff, physicians, and healthcare facilities. Careful documentation of clinical signs and symptoms and estimation of individual radiation dose are required for medical triage. While loss of life in a nuclear detonation may be enormous, the survival benefit afforded those who receive modern supportive care is significant. Effective care requires implementation of a well-organized contingency plan for a scenario that takes into account loss of infrastructure.

Acute exposure to radiation induces a well-defined clinical entity, the so-called ARS with four distinct phases. The main issue in ARS is to prevent radiation-induced organ dysfunction, where the most vulnerable cells and organs are the bone marrow hematopoietic cells and the fixed tissue and organ macrophages.

The main emphasis in early ARS phase is to prevent radiation-induced reduced host defense, where the main risk is aplasia and irreversible organ dysfunction. In order to increase the survival rate after radiation exposure, it is most important to prioritize hematologic recovery. The latest general standard intervention is prompt treatment with growth factors. The United States recommendation is growth factors (G-CSF/ GM-CSF) administered as an infusion/subcutaneous dose for the prevention of loss of host defense in ARS. A level of "high radiation exposure" is arbitrarily chosen in order to not overlook potential bone marrow aplasia, as it is impossible to predict how many victims would develop ARS with clinically significant pancytopenia after radiation exposure. However, an important issue here is the prevention of organ dysfunction. In ARS, organs of the host are driven by fixed tissue macrophages which, after stimulation with GM-CSF, will be transformed into immunocompetent dendritic cells, which in turn finally orchestrate the outer-barriers host against endogenous and exogenous microbiological agents. By the administration of growth factors (G-CSF/GM-CSF) systemically, however, the lung is specifically vulnerable to radioactive exposure as its host is isolated from the rest of the circulation system. The alveolocapillary membrane is sealed off from the systemic pool of drugs for protein-like-medicaments. Proteins are, however, soluble and too large to penetrate the membrane. A novel dual treatment regime after radiation exposure is therefore proposed. The treatment plan emphasizes the importance of prophylactic treatment with both systemically-administered G-CSF/GM-CSF and additional inhaled adequate doses of GM-CSF in order to ensure a hematologic response in the entire body, including the pulmonary system.

Ultimately HSCT should only be considered provided that bone marrow aplasia persists after 3 weeks treatment with high doses of GM-CSF without any response in the neutrocyte count, ie, with no residual hematopoiesis.

\section{Disclosure}

Lars Heslet (LH) has shares in the pharmacompany Serendex ApS Copenhagen, Denmark, which holds a patent related to the inhaled GM-CSF. LH has, however, not received reimbursements, fees, or funding from any organization relating to the content or preparation of this manuscript. LH declares that he has no other competing interests. Steen Nepper-Christensen (SNC) and Christiane Bay (CB) declare that they have no competing financial interests related to the preparation or the content of the manuscript.

All authors read and approved the final manuscript.

\section{References}

1. Radiation injury. In: Fauci AS, Braunwald E, Kasper DL, et al, editors. Harrison's Principles of Internal Medicine. 17th ed. New York, NY: McGraw-Hill Professional; 2008:2559-2568.

2. Hall EJ. Acute effects of total-body irradiation. In: Hall EJ. Radiobiology for the Radiologist. 5th ed. Philadelphia, PA: Lippincott Williams and Wilkins; 2000:117-128.

3. Cerveny TJ, MacVittie TJ, Young RW. Acute radiation syndrome in humans. In: Walker RI, Cerveny TJ, editors. Medical Consequences of Nuclear Warfare. 1989. Falls Church, VA: TMM Publications, Office of the Surgeon General; 1989:17-36.

4. Anno GH, Baum SJ, Withers HR, Young RW. Symptomatology of acute radiation effects in humans after exposure to doses of 0.5-30 Gy. Health Phys. 1989;56(6):821-838.

5. Mettler FA Jr, Gus'kova AK, Gusev I. Health effects in those with acute radiation sickness from the Chernobyl accident. Health Phys. 2007;93(5):462-469.

6. Thongpraparn T, Chaudakshetrin P, Buranapong P. Lesson learned from Co-60 accident in Thailand. Australas Phys Eng Sci Med. 2002;25(4):172-174.

7. Liu Q, Jiang B, Jiang LP, et al. Clinical report of three cases of acute radiation sickness from a (60)Co radiation accident in Henan Province in China. J Radiat Res (Tokyo). 2008;49(1):63-69.

8. Gourmelon P, Benderitter M, Bertho JM, Huet C, Gorin NC, De Revel P. European consensus on the medical management of acute radiation syndrome and analysis of the radiation accidents in Belgium and Senegal Health Phys. 2010;98(6):825-832.

9. Waselenko JK, MacVittie TJ, Blakely WF, et al. Medical management of the acute radiation syndrome: recommendations of the Strategic National Stockpile Radiation Working Group. Ann Intern Med. 2004;140(12):1037-1051.

10. Junk AK, Egner P, Gottloeber P, Peter RU, Stefani FH, Kellerer AM. Long-term radiation damage to the skin and eye after combined beta- and gamma- radiation exposure during the reactor accident in Chernobyl Klin Monbl Augenheilkd. 1999;215(6):355-360. German. 
11. Donnelly EH, Nemhauser JB, Smith JM, et al. Acute radiation syndrome: assessment and management. South Med J. 2010;103(6):541-546.

12. Schull WJ. Effects of Atomic Radiation. New York, NY: Wiley-Liss; 1995.

13. Weisdorf D, Chao N, Waselenko JK, et al. Acute radiation injury: contingency planning for triage, supportive care, and transplantation. Biol Blood Marrow Transplant. 2006;12(6):672-682.

14. Butturini A, De Souza PC, Gale RP, et al. Use of recombinant granulocyte-macrophage colony stimulating factor in the Brazil radiation accident. Lancet. 1988;2(8609):471-475.

15. Brandão-Mello CE, Oliveira AR, Valverde NJ, Farina R, Cordeiro JM. Clinical and hematological aspects of 137Cs: the Goiânia radiation accident. Health Phys. 1991;60(1):31-39.

16. Nagler A, Naparstek E, Drakos P, et al. Interleukin-3 in combination with granulocyte-macrophage-colony-stimulating factor following bone marrow transplantation in a radiation accident victim. Med Oncol. 1994;11(1):27-28.

17. Baranov AE, Selidovkin GD, Butturini A, Gale RP. Hematopoietic recovery after 10-Gy acute total body radiation. Blood. 1994;83(2):596-599.

18. Vorobiev AI. Acute radiation disease and biological dosimetry in 1993. Stem Cells. 1997;15 Suppl 2:269-274.

19. Fliedner TM, Andrews GA, Cronkite EP, Bond VP. Early and late cytologic effects of whole body irradiation on human marrow. Blood. 1964;23:471-487.

20. Fliedner T, Cronkite E, Bond VP. Assessment of radiation effects by molecular and cellular approaches. Stem Cells. 1995;(Suppl 1):13.

21. Fliedner TM. Nuclear terrorism: the role of hematology in coping with its health consequences. Curr Opin Hematol. 2006;13(6):436-444.

22. Gurion R, Gafter-Gvili A, Paul M, et al. Hematopoietic growth factors in aplastic anemia patients treated with immunosuppressive therapy-systematic review and meta-analysis. Haematologica. 2009;94(5):712-719.

23. Anderson PM, Markovic SN, Sloan JA, et al. Aerosol granulocyte macrophage-colony stimulating factor: a low toxicity, lung-specific biological therapy in patients with lung metastases. Clin Cancer Res. 1999;5(9):2316-2323.

24. Wylam ME, Ten R, Prakash UB, Nadrous HF, Clawson ML, Anderson PM. Aerosol granulocyte-macrophage colony-stimulating factor for pulmonary alveolar proteinosis. Eur Respir J. 2006;27(3):585-593.

25. Smith TJ, Khatcheressian J, Lyman GH, et al. 2006 update of recommendations for the use of white blood cell growth factors: an evidence-based clinical practice guideline. J Clin Oncol. 2006;24(19):3187-3205.

26. Weisbart RH, Gasson JC, Golde DW. Colony-stimulating factors and host defense. Ann Intern Med. 1989;110(4):297-303.

27. Schiffer CA. Hematopoietic growth factors as adjuncts to the treatment of acute myeloid leukemia. Blood. 1996;88(10):3675-3685.

28. Nemunaitis J, Rabinowe SN, Singer JW, et al. Recombinant granulocytemacrophage colony-stimulating factor after autologous bone marrow transplantation for lymphoid cancer. N Engl J Med. 1991;324(25):1773-1778.

29. Klumpp TR, Mangan KF, Goldberg SL, Pearlman ES, Macdonald JS. Granulocyte colony-stimulating factor accelerates neutrophil engraftment following peripheral-blood stem-cell transplantation: a prospective, randomized trial. J Clin Oncol. 1995;13(6):1323-1327.

30. Ciernik IF, Schanz U, Gmür J. Delaying treatment with granulocyte colony-stimulating factor after allogeneic bone marrow transplantation for hematological malignancies: a prospective randomized trial. Bone Marrow Transplant. 1999;24(2):147-151.

31. Demirer T, Ayli M, Dagli M, et al. Influence of post-transplant recombinant human granulocyte colony-stimulating factor administration on peritransplant morbidity in patients undergoing autologous stem cell transplantation. Br J Haematol. 2002;118(4):1104-1111.

32. Bence-Bruckler I, Bredeson C, Atkins H, et al. A randomized trial of granulocyte colony-stimulating factor (Neupogen) starting day 1 vs day 7 post-autologous stem cell transplantation. Bone Marrow Transplant. 1998;22(10):965-969.

33. Mayer P, Schütze E, Lam C, Kricek F, Liehl E. Recombinant murine granulocyte-macrophage colony-stimulating factor augments neutrophil recovery and enhances resistance to infections in myelosuppressed mice. J Infect Dis. 1991;163(3):584-590.
34. Rose RM, Kobzik L, Dushay K, et al. The effect of aerosolized recombinant human granulocyte macrophage colony-stimulating factor on lung leukocytes in nonhuman primates. Am Rev Respir Dis. 1992;146(5 Pt 1):1279-1286.

35. Neelis KJ, Dubbelman YD, Qingliang L, Thomas GR, Eaton DL, Wagemaker G. Simultaneous administration of TPO and G-CSF after cytoreductive treatment of rhesus monkeys prevents thrombocytopenia, accelerates platelet and red cell reconstitution, alleviates neutropenia, and promotes the recovery of immature bone marrow cells. Exp Hematol. 1997;25(10):1084-1093.

36. Farese AM, Hunt P, Grab LB, MacVittie TJ. Combined administration of recombinant human megakaryocyte growth and development factor and granulocyte colony-stimulating factor enhances multilineage hematopoietic reconstitution in nonhuman primates after radiationinduced marrow aplasia. J Clin Invest. 1996;97(9):2145-2151.

37. MacVittie TJ, Farese AM, Herodin F, Grab LB, Baum CM, McKearn JP. Combination therapy for radiation-induced bone marrow aplasia in nonhuman primates using synthokine SC-55494 and recombinant human granulocyte colony-stimulating factor. Blood. 1996;87(10): 4129-4135.

38. Neelis KJ, Hartong SC, Egeland T, Thomas GR, Eaton DL, Wagemaker G. The efficacy of single-dose administration of thrombopoietin with coadministration of either granulocyte/macrophage or granulocyte colony-stimulating factor in myelosuppressed rhesus monkeys. Blood. 1997;90(7):2565-2573.

39. Farese AM, Williams DE, Seiler FR, MacVittie TJ. Combination protocols of cytokine therapy with interleukin-3 and granulocyte-macrophage colony-stimulating factor in a primate model of radiation-induced marrow aplasia. Blood. 1993;82(10):3012-3018.

40. Schuening FG, Appelbaum FR, Deeg HJ, et al. Effects of recombinant canine stem cell factor, a c-kit ligand, and recombinant granulocyte colony-stimulating factor on hematopoietic recovery after otherwise lethal total body irradiation. Blood. 1993;81(1):20-26.

41. Schuening FG, Storb R, Goehle S, et al. Effect of recombinant human granulocyte colony-stimulating factor on hematopoiesis of normal dogs and on hematopoietic recovery after otherwise lethal total body irradiation. Blood. 1989;74(4):1308-1313.

42. Nash RA, Schuening FG, Seidel K, et al. Effect of recombinant canine granulocyte-macrophage colony-stimulating factor on hematopoietic recovery after otherwise lethal total body irradiation. Blood. 1994;83(7):1963-1970.

43. Bertho JM, Roy L, Souidi M, et al. New biological indicators to evaluate and monitor radiation-induced damage: an accident case report. Radiat Res. 2008;169(5):543-550.

44. Bertho JM, Roy L. A rapid multiparametric method for victim triage in cases of accidental protracted irradiation or delayed analysis. $\mathrm{Br} \mathrm{J}$ Radiol. 2009;82(981):764-770.

45. Prasanna PG, Blakely WF, Bertho JM, et al. Synopsis of partial-body radiation diagnostic biomarkers and medical management of radiation injury workshop. Radiat Res. 2010;173(2):245-253.

46. Léonard A, Rueff J, Gerber GB, Léonard ED. Usefulness and limits of biological dosimetry based on cytogenetic methods. Radiat Prot Dosimetry. 2005;115(1-4):448-454.

47. Sevan'kaev AV, Golub EV, Khvostunov IK, et al. Retrospective dose estimation in remote period after exposure using different biological methods. Radiats Biol Radioecol. 2004;44(6):637-652. Russian.

48. Heslet L. Look on the "air side" in pneumonia. Crit Care Med. 2009; 37(2):774-775.

49. Brand P, Beckmann H, Maas Enriquez M, et al. Peripheral deposition of alpha1-protease inhibitor using commercial inhalation devices. Eur Respir J. 2003;22(2):263-267.

50. Liu KD, Levitt J, Zhuo H, et al. Randomized clinical trial of activated protein $\mathrm{C}$ for the treatment of acute lung injury. Am J Respir Crit Care Med. 2008;178(6):618-623.

51. Heslet L, Andersen JS, Sengeløv H, Dahlbäck B, Dalsgaard-Nielsen J. Inhalation of activated protein $\mathrm{C}$ : A possible new adjunctive intervention in acute respiratory distress syndrome. Biologics. 2007;1(4):465-472. 
52. Waerhaug K, Kuzkov VV, Kuklin VN, et al. Inhaled aerosolised recombinant human activated protein $\mathrm{C}$ ameliorates endotoxin-induced lung injury in anaesthetised sheep. Crit Care. 2009;13(2):R51.

53. Sangwan S, Agosti JM, Bauer LA, et al. Aerosolized protein delivery in asthma: gamma camera analysis of regional deposition and perfusion. J Aerosol Med. 2001;14(2):185-195.

54. Luisetti M, Kroneberg P, Suzuki T, et al. Physical properties, lung deposition modeling, and bioactivity of recombinant GM-CSF aerosolised with a highly efficient nebulizer. Pulm Pharmacol Ther. 2011;24(1):123-127.

55. Robinson TE, Trapnell BC, Goris ML, Quittell LM, Cornfield DN. Quantitative analysis of longitudinal response to aerosolized granulocytemacrophage colony-stimulating factor in two adolescents with autoimmune pulmonary alveolar proteinosis. Chest. 2009;135(3):842-848.
56. Price A, Manson D, Cutz E, Dell S. Pulmonary alveolar proteinosis associated with anti-GM-CSF antibodies in a child: successful treatment with inhaled GM-CSF. Pediatr Pulmonol. 2006;41(4):367-370.

57. Rao RD, Anderson PM, Arndt CA, Wettstein PJ, Markovic SN. Aerosolized granulocyte macrophage colony-stimulating factor (GM-CSF) therapy in metastatic cancer. Am J Clin Oncol. 2003;26(5):493-498.

58. Belyi D, Kovalenko A, Bazyka D, Bebeshko V. Non-cancer effects in acute radiation syndrome survivors in Ukraine. Health Phys. 2010;98(6):876-884.

59. Baranov A, Gale RP, Guskova A, et al. Bone marrow transplantation after the Chernobyl nuclear accident. $N$ Engl J Med. 1989;321(4): 205-212.

60. Gale RP, Reisner Y. The role of bone-marrow transplants after nuclear accidents. Lancet. 1988;1(8591):923-926.
International Journal of General Medicine

\section{Publish your work in this journal}

The International Journal of General Medicine is an international peer-reviewed open-access journal that focuses on general and internal medicine, pathogenesis, epidemiology, diagnosis, monitoring and treatment protocols. The journal is characterized by the rapid reporting of reviews, original research and clinical studies across all disease areas.

\section{Dovepress}

A key focus is the elucidation of disease processes and management protocols resulting in improved outcomes for the patient.The manuscript management system is completely online and includes a very quick and fair peer-review system. Visit http://www.dovepress.com/ testimonials.php to read real quotes from published authors.

Submit your manuscript here: http://www.dovepress.com/international-journal-of-general-medicine-journal 